\title{
Estudo Preliminar sobre a ecologia de Lontra longicaudis (Olfers) (Carnivora, Mustelidae) no Vale do Taquari, Sul do Brasil
}

\author{
Carlos Benhur Kasper, Maria Júlia Feldens, Juliana Salvi \& Hamilton César Zanardi Grillo
}

Museu de Ciências Naturais, Centro Universitário UNIVATES. Rua Avelino Tallini 171, 95900-000 Lajeado, Rio Grande do Sul, Brasil. E-mail: felinosdosul@yahoo.com.br

\begin{abstract}
Preliminary Study by the ecology of Lontra longicaudis (Olfers) (Carnivora, Mustelidae) in Taquari Valley, South Brazil. The study was carried out in two areas of Taquari Valley, central region of Rio Grande do Sul State, Southern Brazil. Between August 2000 and December 2001 a study about diet and use of shelters and scent marks by Lontra longicaudis (Olfers, 1818) was performed. 275 spraints were colleted, of which 261 were analised for diet determination. The use of scent marks occured by the deposition of feaces mainly under conspicuous sites of the river margin or inside the shelters. The shelters were often formed by parallel excavation of river margin. The shelters were highly reused. Predation occurred on 3 groups of preys: Fish, Mammals and Insects. The fish, formed the diet base, and the families Loricariidae/Callichthyidae, Cichlidae, Pimelodidae/ Auchenipteridae and Erythrinidae were the most frequently identified ones in fecal analysis. The occurrence of these fish groups in the diet was higher then the relative availability in environment.
\end{abstract}

KEY WORDS. Diet, otter, Rio Grande do Sul, scent marks, shelters.

RESUMO. O estudo foi realizado em duas áreas no Vale do Taquari, região central do Estado do Rio Grande do Sul, Sul do Brasil. Entre agosto de 2000 e dezembro de 2001 foi realizado um estudo sobre a dieta e o uso de abrigos e marcas odoríferas por Lontra longicaudis (Olfers, 1818). Coletaram-se 275 marcas odoríferas, das quais 261 foram analisadas para determinação da dieta. O uso de marcas odoríferas ocorreu por deposição de fezes, sobretudo sobre locais conspícuos das margens dos rios ou no interior dos abrigos. Os abrigos foram formados principalmente por escavação paralela a margem dos rios. Estes abrigos foram altamente reutilizados. Ocorreu predação sobre três grupos de presas: peixes, mamíferos e insetos. Os peixes formam a base da dieta, e as famílias Loricariidae / Callichthyidae, Cichlidae, Pimelodidae / Auchenipteridae e Erythrinidae foram as mais freqüentes nas análises fecais. A ocorrência destes grupos de peixes na dieta é maior do que sua disponibilidade relativa no ambiente.

PALAVRAS CHAVE. Abrigos, dieta, lontra, marcações odoríferas, Rio Grande do Sul.

A lontra neotropical é um mustelídeo aquático de ampla distribuição, podendo ser encontrado do México ao Uruguai e Argentina e praticamente em todo Brasil (EISEMBERG \& REDFord 1999). É encontrada em rios e córregos do continente, embora possa utilizar ambientes marinhos e de água salobra (BLACHER 1987).

A taxonomia do gênero tem sido discutida, mas a atual tendência é a adoção do gênero Lontra para as lontras de rio do novo mundo (LaRIVIÈre 1999).

Carnívoros em geral, têm por hábito defecar em locais conspícuos e proeminentes da sua área de vida (WeImMER et al. 1996). Este comportamento é o foco da maioria dos estudos envolvendo lontras, sendo utilizado para a definição de áreas de ocorrência (СhehebAR 1985, ChehebAR et al. 1986, BlaCher 1987) e estudos de dieta (Beja 1991, Brzezinski et al. 1993, Passamani \&
Camargo 1995, Pardini 1998, Quadros \& Monteiro-Filho 2001). A utilização de marcas odoríferas por Lontra longicaudis (Olfers, 1818) é um aspecto marcante de seu comportamento, (Sí́nola \& Vaughan 1995, Soldateli \& Blacher 1996, Quadros \& Montero-Filho 2002). Porém, seu papel na vida social desta espécie, bem como da maioria das espécies que as utilizam, tem sido pouco enfocado (Gorman \& Trowbridge 1989). De forma geral, este comportamento é observado pela deposição de fezes e muco anal em locais conspícuos do ambiente e no interior de abrigos, embora possam ser encontrados em outros locais (SOLDATELI \& Blacher 1996).

As lontras possuem hábitos esquivos, assim como a maioria dos carnívoros. Sendo assim, a maioria dos estudos envolvendo a espécie faz uso de métodos indiretos de observação (Blacher 1987, Passamani \& Camargo 1995, Spínola \& Vaughan 
1995, Soldateli \& Blacher 1996, PARdini 1998, Quadros \& MonteiroFILHo 2001,). Segundo RedFord (1997), estudos mostram que a presença de predadores pode aumentar a diversidade geral de espécies numa comunidade. Entretanto, os efeitos de predadores aquáticos nos ecossistemas neotropicais tem sido pouco estudados, tornando ainda mais urgente o estudo das interações desta espécie com o ambiente local.

Assim, tendo em vista a carência de estudos sobre a lontra neotropical, este trabalho tem como objetivo o estudo da utilização de marcas odoríferas e abrigos por Lontra longicaudis, além de avaliar a composição da dieta e sua relação com os ambientes estudados.

\section{MATERIAL E MÉTODOS}

\section{Área de estudo}

O estudo foi realizado em duas áreas da porção baixa da sub-bacia do Rio Forqueta pertencente à bacia hidrográfica do Rio Taquari-Antas. Situadas na região do Vale do Taquari, Estado do Rio Grande do Sul, as áreas apresentam vegetação do tipo floresta estacional decidual (FolHA SH 22 1986).

A área A, localiza-se nas coordenadas $29^{\circ} 24^{\prime} 45^{\prime \prime} \mathrm{S}$ e $52^{\circ} 01^{\prime} 38^{\prime \prime} \mathrm{W}$, correspondendo a um trecho de $1.200 \mathrm{~m}$, na porção final do Arroio Forquetinha. O local apresenta margens com declividade acentuada, com aproximadamente $40^{\circ}$ de inclinação, tendo em média 8 metros de altura em relação ao nível médio da água. A vegetação ciliar apresenta porções bem conservadas e porções degradadas com fortes sinais de erosão, onde há um predomínio de vegetação secundária em estágio primário de regeneração. Nesta área, não existem afloramentos de rocha e nenhum tipo de matacão nas margens, sendo estas constituídas por barrancos de terra e seixos.

A área B, localiza-se nas coordenadas $29^{\circ} 05^{\prime} 03^{\prime \prime} \mathrm{S}$ e $52^{\circ} 12^{\prime} 24^{\prime \prime} \mathrm{W}$, no Rio Forqueta, área de implantação da Pequena Central Hidrelétrica Salto Forqueta. A área apresenta três pontos de coleta, com aproximadamente $800 \mathrm{~m}$ cada. Neste ambiente é possível observar a presença de inúmeras formações rochosas e matacões de rocha nas margens. A mata ciliar da área apresenta-se em bom estado de conservação, com exceção da área de formação do lago da barragem, onde a vegetação foi retirada para o enchimento da represa.

\section{Coleta de dados}

Foram realizadas 20 saídas a campo entre agosto de 2000 e dezembro de 2001, distribuídas nas quatro estações do ano.

Coletas de fezes foram realizadas a partir da vistoria das margens, percorridas a pé à procura de latrinas e abrigos utilizados por Lontra longicaudis. Por latrinas, são entendidos neste estudo, todos os sítios de defecação identificados com fezes de lontra, localizados fora de áreas cobertas que poderiam estar servindo de abrigo para a espécie. Por abrigos são entendidos todos os locais cobertos ou que ofereçam alguma proteção às lontras, e que apresentaram algum indício de utilização pela espécie tal como pegadas e/ou fezes.
As marcas odoríferas foram identificadas por seu odor e forma característicos, sendo classificadas quanto a sua constituição (fezes ou muco-anal sem resíduos alimentares) e conforme o local de deposição (latrina ou abrigo). Todos as fezes foram coletados para análise dos itens alimentares que haviam sido ingeridos.

Cada abrigo identificado foi descrito quanto a sua estrutura, dimensões e monitorado quanto a sua reutilização, tendo como principal indício de utilização, a presença de fezes em seu interior.

\section{Análise de laboratório}

A dieta foi estudada a partir da análise de conteúdo fecal. Em laboratório, as fezes foram lavadas em água corrente, sobre peneira de malha fina, obtendo o material residual de peças duras. $\mathrm{O}$ material foi conservado em recipientes individuais por amostra fecal, em solução de álcool a 70\% para posterior triagem. A triagem foi realizada manualmente com o auxílio de lupa, selecionando as estruturas que pudessem servir para a identificação dos constituintes de cada amostra, tais como escamas, raios duros, ossos, dentes e carapaças. Todas as estruturas selecionadas foram comparadas a coleção de referência para determinação do táxon consumido.

A freqüência de ocorrência de cada táxon na dieta foi calculada pela divisão do total de vezes em que o item esteve presente pelo número total de amostras, e expressa em porcentagem.

A dieta apresentada por Lontra longicaudis nas duas áreas foi comparada com a utilização do teste de Mann-Whitney (ZAR 1999). O teste avaliou a existência, ou não, de diferença significativa na composição da dieta apresentada nas áreas $\mathrm{A}$ e B deste estudo.

A dieta apresentada na área $\mathrm{B}$ pode ser comparada $\mathrm{a}$ disponibilidade de peixes do ambiente. Para tanto, além da comparação direta entre a disponibilidade e as freqüências de ocorrência na dieta, foi aplicado o Rank Preference Index, descrito por KREBs (1998).

\section{Amostragem da disponibilidade de peixes}

O estudo da ecologia de L. longicaudis na área B foi realizado como parte do plano de monitoramento ambiental da implantação da Pequena Central Hidrelétrica Salto Forqueta, que incluía, entre outros, o estudo da ictiofauna local. Desta forma, os resultados destes estudos puderam ser comparados nesta área, fornecendo informações mais precisas sobre o padrão de alimentação de L. longicaudis.

Assim, a amostragem de peixes foi realizada apenas na área B. Para a captura foram utilizadas seis redes de espera, de três malhas diferentes $(1.5,2.5$ e $3.5 \mathrm{~cm}$ entre nós) mantidas por períodos de $24 \mathrm{~h}$. O método foi aplicado em diversos pontos da área de estudo, ao longo de 11 saídas a campo, abrangendo as quatro estações do ano, totalizando $264 \mathrm{~h}$ de captura. O método de coleta foi adaptado de Benedito-Cecilio \& Agostinho (2000). 


\section{RESULTADOS}

\section{Utilização de marcas odoríferas}

As marcas odoríferas foram encontradas em dois tipos de locais: no interior de abrigos e em latrinas. No total foram recolhidas 275 marcas odoríferas.

As latrinas foram, na maioria das vezes, compostas por rochas, matacões ou troncos caídos, sempre muito próximo à margem ou projetado para dentro do leito do rio. Em alguns casos, foram encontradas fezes de lontras em meio à vegetação na margem do rio.

$\mathrm{Na}$ área $\mathrm{A}$, foram encontradas 131 marcas odoríferas compostas por 123 fezes e oito mucos-anais (Fig. 1). Destas, 119 marcas $(90,8 \%)$ foram encontradas no interior de abrigos e apenas 12 marcas $(9,2 \%)$ foram encontradas em latrinas (Fig. 2).

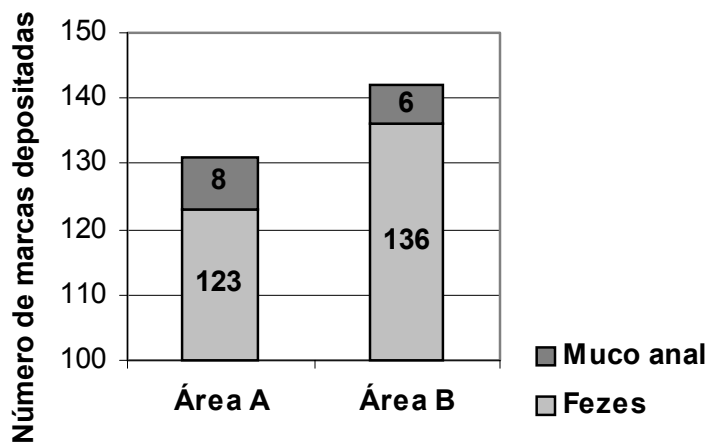

Figura 1. Freqüência de deposição de fezes e muco-anal por Lontra longicaudis no Arroio Forquetinha (área A) e Rio Forqueta (área B).

$\mathrm{Na}$ área B, foram encontradas 144 marcas odoríferas, correspondendo a 138 fezes e seis mucos-anais (Fig. 1). Do total, 62 marcas $(43,5 \%)$ foram encontradas no interior de abrigos e 82 marcas (57 \%) foram encontradas em latrinas (Fig. 2).

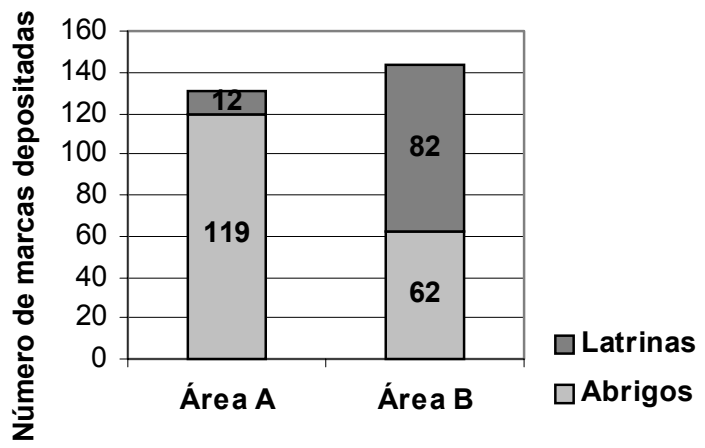

Figura 2. Freqüência de marcas odoríferas de Lontra longicaudis depositadas em abrigos e latrinas no Arroio Forquetinha (área A) e Rio Forqueta (área B).

\section{Utilização de Abrigos}

$\mathrm{Na}$ área $\mathrm{A}$, foram encontrados seis abrigos, sendo dois destes construídos por escavação em meio a um barranco coberto por vegetação secundária em estágio primário de regeneração. Estes abrigos foram destruídos na primeira grande enxurrada, ocorrida no início das atividades. Os demais abrigos foram construídos por escavação paralela à margem do rio, sob raízes, em meio à mata ciliar preservada. Estes abrigos permaneceram intactos mesmo após três enxurradas, nas quais foram cobertos completamente pela água, não acarretando modificações em seu padrão de utilização, uma vez que continuaram a ser encontradas marcas odoríferas e sinais de escavação.

Os abrigos da área A, encontravam-se em média a 4,67 m $( \pm 1,19 \mathrm{~m})$ da margem e a $4,07 \mathrm{~m}( \pm 1,18 \mathrm{~m})$ de altura em relação ao nível do rio, com comprimentos e profundidades bastante variáveis.

A utilização destes abrigos mostrou-se bastante constante, apresentando uma reutilização média de 69,2\%. Um dos abrigos foi reutilizado em todas as ocasiões, onde foi encontrado um total de 77 marcações odoríferas, ou 58,8\% do total de marcas odoríferas encontradas na área $\mathrm{A}$.

$\mathrm{Na}$ área $\mathrm{B}$ foram encontrados seis abrigos. Destes, cinco localizavam-se entre formações rochosas, apresentando dimensões e distâncias variáveis em relação à margem. Apenas um abrigo foi encontrado sob raízes, tendo sido utilizado uma vez. Os demais abrigos apresentaram freqüências de reutilização mais elevadas, perfazendo $76 \%$ de reutilização média, sendo que um dos abrigos foi utilizado em todas as ocasiões. Por comparação entre as duas áreas, observa-se que na área $\mathrm{B}$, onde existe a disponibilidade de abrigos naturais prontos entre rochas, há pouca utilização de abrigos sob raízes.

Em ambas as áreas todos os abrigos foram constituídos por uma única câmara, formada pela sobreposição de rochas ou pela escavação sob raízes.

Dieta

A dieta foi analisada a partir da triagem de 261 fezes e de dois restos alimentares, num total de 263 amostras.

$\mathrm{Na}$ área $\mathrm{A}$, foram recolhidas 123 amostras fecais. Através da análise das fezes foi possível identificar seis grupos básicos de presas: $89 \%$ das amostras continham peixes, sendo este o item mais importante de sua alimentação, mamíferos em 8,8\%, artrópodes em 5,6\%, aves em 1,6\%, anfíbios em 0,8\% e moluscos também em $0,8 \%$ das amostras. Além disto em uma das amostras não foi possível à identificação dos constituintes residuais, em função da deterioração do material (Fig. 3).

Entre os mamíferos, identificou-se a presença de roedores e de carniça proveniente de uma carcaça de boi, observada na área de estudo. A utilização da carcaça pôde ser comprovada pela identificação de pêlos de boi nas fezes.

Entre os artrópodes, destaca-se a ocorrência da ordem Megaloptera, verificada em seis amostras, ou 4,8\%, e o baixo índice de predação sobre crustáceos, identificado em apenas uma amostra (Tab. I).

Revista Brasileira de Zoologia 21 (1): 65-72, março 2004 


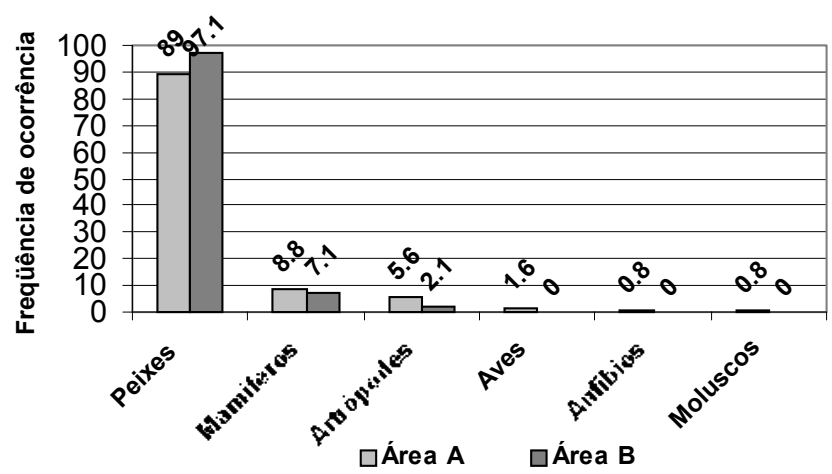

Figura 3. Freqüência das categorias alimentares encontradas em amostras fecais de Lontra longicaudis no Arroio Forquetinha (área A) e Rio Forqueta (área B).

Entre os peixes foi possível verificar o consumo sobre oito famílias de peixes autóctones e uma espécie exótica, Cyprinus carpius(Linnaeus, 1758). As freqüências de ocorrência nas amostras são: Loricariidae/Callichthyidae, em 57,5 \%, Cichlidae, em 47,8\%, Pimelodidae/Auchenipteridae, em 23,5\%, Erythrinidae, em $14,5 \%$, Curimatidae em $12,1 \%$ e Characidae em 2,4\%. Além destas famílias, observou-se a ocorrência de Cyprinus carpius em 4,8\% das amostras. Verificou-se ainda que $13,7 \%$ das amostras continham peixes, onde não foi possível a determinação da família consumida, permanecendo, desta maneira, como peixes não identificados (Fig. 4).

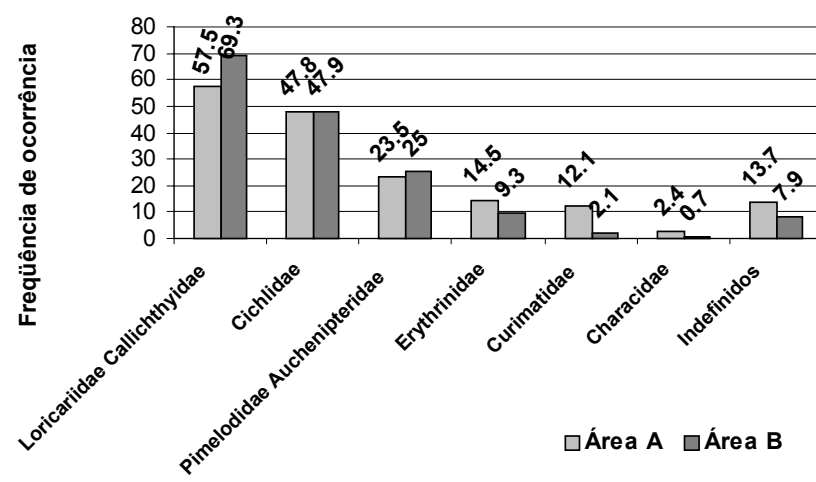

Figura 4. Freqüências de ocorrência de peixes na dieta de Lontra longicaudis no Arroio Forquetinha (área A) e Rio Forqueta (área B).

$\mathrm{Na}$ área $\mathrm{B}$, foram recolhidas 138 amostras fecais e dois restos alimentares, somando então 140 amostras. A análise da dieta identificou três grupos básicos de presas, assim distribuídos: peixes, presentes em 97,1\% das amostras, artrópodes em $7,1 \%$ e mamíferos em $2,1 \%$. Em uma amostra não foi possível a identificação de seus constituintes (Fig. 3).
Novamente, destaca-se a ocorrência da ordem Megaloptera, como o principal artrópode predado e o único representativo na dieta da lontra. Entre os mamíferos consumidos, foram identificados indivíduos pertencentes à ordem Rodentia (Tab. I).

Entre os peixes foi possível verificar a predação sobre as mesmas oito famílias e a mesma espécie exótica, observada na área $\mathrm{A}$. As freqüências de ocorrência neste caso ocorreram da seguinte maneira: Loricariidae/Callichthyidae, presente em $69,3 \%$ das amostras, Cichlidae em 47,9\%, Pimelodidae/ Auchenipteridae em 25\%, Erythrinidae em 9,3\%, Curimatidae em $2,1 \%$ e Characidae em $0,7 \%$. Além destas famílias, observou-se a ocorrência de Cyprinus carpius em 2,8\% das amostras, e em $7,9 \%$ a presença de peixes, nos quais não foi possível uma determinação taxonômica precisa (Fig. 4).

Com a aplicação do teste de Mann-Whitney, que comparou a composição da dieta das áreas A e B, foi obtido $\mathrm{U}=$ 49.500 ( $p=0,4528)$, indicando não haver significância estatística entre as duas áreas amostradas.

\section{Comparação entre a disponibilidade de peixes da área B e}

\section{a ocorrência na dieta}

A partir da coleta de 2625 peixes, observou-se que as famílias Characidae, Loricariidae e Curimatidae são as mais abundantes da ictiofauna da área $\mathrm{B}$, representando respectivamente 50,2\%, 29,3\% e 10,4\% dos espécimes coletados (Tab. II).

Comparando a disponibilidade de peixes verificada na área B, à ocorrência deste grupo na dieta da população de lontras do local, verifica-se a ocorrência de um consumo preferencial pelos grupos Loricariidae/Callichthyidae, Cichlidae, Pimelodidae/Auchenipteridae e Erythrinidae, por apresentarem taxas de predação maiores do que a disponibilidade no ambiente (Fig. 5). Com a utilização do Ranking de Preferência Alimentar (KREBs 1998) observamos que as famílias Pimelodidae/ Auchenipteridae apresentam a maior preferência, seguido pelos ciclídeos e após pelas famílias Loricaridae/Callichthyidae e Erythrinidae (Fig. 6). As famílias Curimatidae e Characidae apresentam ranking positivo o que demonstra possuírem menor preferência na seleção de alimento apresentada por $L$. longicaudis neste estudo (Fig. 6).

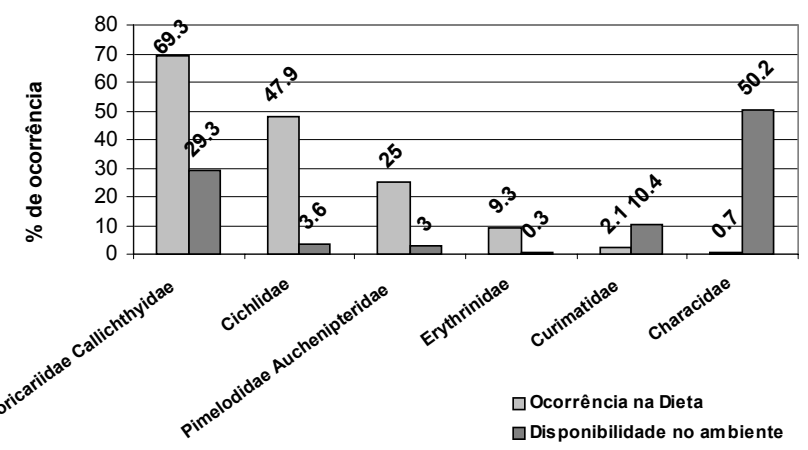

Figura 5. Relação entre a predação por Lontra longicaudis e a disponibilidade de peixes no Rio Forqueta. 
Tabela I. Freqüência absoluta e porcentagem de ocorrência dos grupos predados nas áreas A e B.

\begin{tabular}{|c|c|c|c|c|c|}
\hline \multirow{2}{*}{ Classe } & \multirow{2}{*}{ Grupo } & \multicolumn{3}{|c|}{ Número de amostras } & \multirow{2}{*}{$\begin{array}{l}\text { Porcentagem total de } \\
\text { occorrência (\%) }\end{array}$} \\
\hline & & Área $A(N=123)$ & Área $B(N=138)$ & Total & \\
\hline \multirow[t]{8}{*}{ Peixes } & Loricariidae e Callichthyidae & 71 & 97 & 168 & 63,9 \\
\hline & Cichlidae & 59 & 67 & 126 & 49,0 \\
\hline & Pimelodidae e Achenipteridae & 29 & 35 & 64 & 24,3 \\
\hline & Curimatidae & 15 & 3 & 18 & 6,6 \\
\hline & Erythrinidae & 18 & 13 & 31 & 11,8 \\
\hline & Characidae & 03 & 1 & 04 & 1,5 \\
\hline & Cyprinus carpius & 06 & 4 & 10 & 3,8 \\
\hline & Indefinidos & 17 & 11 & 28 & 10,6 \\
\hline \multirow[t]{4}{*}{ Artrópodes } & Megaloptera & 6 & 7 & 13 & 4,9 \\
\hline & Crustacea & 1 & - & 1 & 0,4 \\
\hline & Diptera & - & 1 & 1 & 0,4 \\
\hline & Belostomatidae & - & 2 & 2 & 0,8 \\
\hline \multirow[t]{3}{*}{ Mamíferos } & Rodentia & 4 & 2 & 6 & 2,3 \\
\hline & Carcaça de boi & 1 & - & 1 & 0,4 \\
\hline & Mamíferos Indefinidos & 6 & 1 & 7 & 2,7 \\
\hline Aves & Aves & 2 & - & 2 & 0,8 \\
\hline Moluscos & Molusca & 1 & - & 1 & 0,4 \\
\hline Anfíbios & Anphibia & 1 & - & 1 & 0,4 \\
\hline Indefinidos & & 1 & 1 & 1 & 0,4 \\
\hline
\end{tabular}

Tabela II. Porcentagem de ocorrência das principais famílias de peixes observados na área B.

\begin{tabular}{cccccccc}
\hline & Loricariidae & Cichlidae & Pimelodidae & Curimatidae & Erythrinidae & Characidae & Outras famílias \\
\hline Ocorrência (\%) & 29,3 & 3,6 & 3,0 & 10,4 & 0,3 & 50,2 & 3,2 \\
\hline
\end{tabular}

\begin{tabular}{|c|c|c|c|c|c|c|c|c|c|}
\hline \multicolumn{8}{|c|}{+ Preferidos } & \multicolumn{2}{|c|}{ - Preferidos } \\
\hline-3 & -2 & -1 & 0 & 1 & 2 & 3 & 4 & 5 & 6 \\
\hline
\end{tabular}

Figura 6. Índice de Preferência Alimentar apresentado por Lontra longicaudis no Rio Forqueta.

\section{DISCUSSÃO}

A utilização de marcas odoríferas por Lontra longicaudis deu-se pela deposição de fezes e muco-anal sobre latrinas e no interior de abrigos tal como outros trabalhos relatam (PARDINI \& Trajano 1999, Colares \& Waldemarin 2000, Quadros \& MonteiroFiLHo 2002). Neste trabalho constatou-se a utilização de mucoanal de forma análoga às fezes, sendo possível supor que o muco-anal desempenhe funções semelhantes às fezes, embora com freqüência de deposição mais baixa.

Quanto aos locais de deposição das marcas odoríferas, puderam ser observados padrões diferenciados para as duas áreas, conforme a constituição de suas margens. Observou-se um maior número de marcas depositadas no interior de abrigos na área A (90,8\% das marcas coletadas neste ambiente) onde existiam poucos locais conspícuos nas margens.

O trabalho de Quadros e MonTeIro-Filho (2002) em Volta Velha, Santa Catarina, também encontrou um maior número de fezes no interior de abrigos do que em outros locais de deposição. Estes autores consideraram duas variáveis para explicar este fato: um maior número de fezes depositadas no interior ou próximos aos abrigos, e uma maior permanência das marcas odoríferas no interior dos abrigos em relação a locais abertos. No presente trabalho, segundo a análise dos ambientes encontrados na área de estudo, podemos sugerir 
uma nova hipótese, que não invalida as anteriores. Assim, a acentuada deposição de marcas no interior de abrigos, observada na área $\mathrm{A}$, pode refletir a baixa disponibilidade de locais conspícuos no ambiente. Assim, é possível que a falta de locais conspícuos possa favorecer a deposição de marcas odoríferas no interior abrigos.

Em relação aos tipos de abrigos utilizados, observou-se que a espécie apresentou certa preferência pela utilização de abrigos "naturais", sobretudo àqueles formados por espaços entre rochas. $\mathrm{Na}$ ausência destes, as lontras podem escavar os barrancos, especialmente sob raízes de árvores, que naturalmente apresentam um processo erosivo inicial, formando abrigos com a entrada ampla e de forma paralela à margem do rio. Este fato demonstra a importância da conservação da mata ciliar, permitindo a existência de diversos abrigos, conferindo-lhes maior resistência e evitando que estes sejam destruídos facilmente pelas enxurradas.

Tais conformações de abrigos foram descritas por PARDINI \& Trajano (1999), para uma população de lontras no estado de São Paulo, Brasil. Assim a utilização deste tipo de abrigos parece possuir um padrão relativamente definido.

Na utilização de abrigos pode-se observar que as taxas de reutilização foram altas, onde, neste estudo, foi observada uma taxa de reutilização de $100 \%$ para dois dos abrigos monitorados, enquanto a média de utilização dos demais abrigos foi de $63 \%$. Assim, determinados abrigos parecem ter mais importância, ou serem preferidos, em relação a outros. No estudo de Pardini e Trajano (1999), no Rio Betari, também foi sugerido a existência de preferência por determinados abrigos.

A dieta apresentou um padrão definido entre as duas áreas não havendo diferenças significativas entre a composição de dieta destas áreas. Entre os grupos consumidos, os peixes formam a base da dieta da espécie. Estes resultados estão de acordo com a maioria dos trabalhos sobre a dieta da lontra neotropical (PARDini 1998, Colares \& Waldemarin 2000, QuAdros $\&$ Monteiro-Filho 2001), que apresentaramm este item como o mais freqüente. Neste estudo foram verificados índices baixos de consumo de outros itens alimentares, sobretudo no que se refere aos crustáceos, como será discutido mais adiante. Além disso, foi constatada o consumo de restos de uma carcaça de boi observada na área de estudo, o que ilustra um caráter oportunista para a espécie, pouco descrito em trabalhos precedentes.

O consumo de peixes em grande proporção por $L$. longicaudis, possivelmente reflete um comportamento de caça ativo, embora não hajam trabalhos registrando tal comportamento na natureza. Assim, acreditamos que grande parte dos peixes consumidos foram de fato predados pela espécie, e que o eventual consumo de animais mortos ou deixados por outros predadores, provavelmente não influencia de forma substancial nas análises deste estudo.

Entre os grupos de peixes mais predados, destacam-se as famílias Loricariidae/ Callichthyidae, Cichlidae e Pimelodidae/
Auchenipteridae, respectivamente apresentando 63,9\%, 49,0\% e $24,3 \%$ de ocorrência no total de fezes das duas áreas (Tab. I). Para PARdini (1998) Loricariidae é a família mais predada, porém não apresentando outros grupos de peixes com taxas de consumo elevadas, no ambiente estudado. Para Quadros \& Monteiro-Filho (2001) as famílias Cichlidae e Pimelodidae surgem como os grupos de peixes mais consumidos, porém com freqüências de ocorrência bem mais baixas do que as apresentadas por este trabalho. Seria plausível supor, que a diferença entre a constituição da dieta deste estudo esteja relacionada a uma maior disponibilidade de outros itens alimentares, sobretudo ao de crustáceos, muito consumidos em ambos os estudos.

Na área B, foi possível verificar a disponibilidade de peixes no ambiente e, desta forma, avaliar padrões de predação. Foi constatado que existe uma predação preferencial sobre os grupos Loricariidae/Callichthyidae, Cichlidae, Pimelodidae/ Auchenipteridae e Erythrinidae que apresentaram freqüências de consumo mais elevada do que sua ocorrência relativa no ambiente (Fig. 5). De forma semelhante, PARdini (1998) e QUADRos \& MonTeIro-Filho (2001) verificam índices de consumo maiores do que o esperado para alguns grupos.

A ocorrência das famílias Loricariidae, Cichlidae e Pimelodiae entre os grupos mais consumidos, pode estar relacionados aos hábitos destas espécies. Segundo Косн et al. (2000) as espécies da família Loricariidae costumam alimentar-se de detritos, algas, insetos e pequenos crustáceos sempre junto ao substrato onde passam boa parte do tempo. Os peixes da família Cichlidae costumam ser relativamente sedentários e apresentar comportamento territorial (КосH et al. 2000), o que pode facilitar sua predação. Ainda segundo este autor os pimelodídeos em geral freqüentam o fundo dos corpos d'água onde encontram seu alimento, freqüentemente permanecendo entocados durante o dia. Assim, é possível supor que hábitos mais sedentários e bentônicos estejam associados a um maior consumo por L. longicaudis, provavelmente porque estes hábitos facilitam sua captura.

A utilização de redes de espera para amostragem de peixes na área B pode ter amostrado de forma desigual determinados grupos, por encontrar-se estática e capturando apenas peixes que nela colidem durante seus deslocamentos. Todavia, devido ao baixo custo e facilidade de aplicação, o método foi adotado, permitindo a obtenção de dados básicos sobre a ictiofauna local. Embora possa haver algumas distorções quanto à disponibilidade de peixes da área em questão, acreditamos que a comparação geral é valida por terem sido empregadas metodologias padronizadas e consagradas. Não obstante, e necessário deixar claro que este foi um estudo básico, e que somente estudos mais detalhados poderão apresentar dados mais precisos.

Pardini (1998) e Quadros \& Monteiro-Filho (2001) encontraram altos índices de ocorrência de crustáceos em seus estudos. Por outro lado, neste estudo, o consumo de animais des- 
te grupo foi praticamente insignificante, tendo ocorrido em apenas uma amostra do total triado. É provável que este seja reflexo da aparente baixa abundância de crustáceos nas áreas de estudo. Por outro lado verifica-se um consumo mais acentuado e diversificado sobre peixes, quando comparada aos trabalhos precedentes. Poderia-se inferir que a menor diversidade de peixes consumidos, ou as baixas freqüências de predação sobre peixes, encontradas pelos autores acima citados, estejam associados a uma maior disponibilidade de crustáceos no ambiente, e que nas áreas onde verifica-se uma menor disponibilidade deste recurso, há um aumento na intensidade de predação sobre peixes.

De forma geral, pode-se observar uma certa plasticidade em relação à dieta de Lontra longicaudis, apesar da espécie apresentar preferência por determinados itens alimentares, variando conforme o ambiente. Considera-se que há necessidade de realização de novos estudos, para melhor avaliar a plasticidade dos hábitos alimentares e da utilização do ambiente por esta espécie.

\section{AGRADECIMENTOS}

Agradecemos ao Biol. Marco Antônio Majolo e colaboradores (levantamento ictiológico), Dr. Eduardo Périco (estatística e revisão), Dra. Susi Missel Pacheco e ao Dr. Noeli Juares Ferla (revisão final), MSc. Helen Waldemarin e os acadêmicos Alice Hirshmann, Rafael Rodrigo Eckhardt e amigos, pelo apoio, amizade e companheirismo durante toda a execução do projeto. Especial agradecimento ao Centro Universitário UNIVATES e CERTEL pelo apoio e financeiro ao projeto.

\section{REFERÊNCIAS BIBLIOGRÁFICAS}

BEJA, P.R. 1991. Diet of otters (Lutra lutra) in closely associated freshwater, brackish and marine habitat in south-west Portugal. Journal of Zoology, London, 225: 141-152.

Benedito-Cecílio, E. \& A.A. Agostinho. 2000. Distribution, abundance and use of different environments by dominant ichthyofauna in the influence area of Itaipu Reservoir. Acta Scientiarum, Maringá, 22 (2): 429-437.

Blacher, C. 1987. Ocorrência e preservação de Lutra longicaudis (Mammalia: Mustelidae) no litoral de Santa Catarina. Boletim da Fundação Brasileira para Conservação da Natureza, Rio de Janeiro, 22: 105-117.

BREZINSKI, M.; W. JedREZejeWSKI \& B. JedReZejeWsKa. 1993. Diet of otters (Lutra lutra) inhabiting small rivers in the Bialowieza National Park, eastern Poland. Journal of Zoology, London, 230: 495-501.

CheHéber, C.E. 1985. A Survey of the Southern River Otter Lutra provocax Thomas in Nahuel Huapi National Park, Argetina. Biological Conservation, Kidlington, 32: 299-307.

Chehébar C.E.; A. Gallur; G. Giannico; M.D. Gottelli \& P. Yorio. 1986. A Survey of the Southern River Otter Lutra provocax in Lanin, Puelo and Los Alerces National Parks, Argentina, amd Evaluation of its Conservation Status. Biological Conservation, Kidlington, 38: 293-304.

Colares, E.P. \& H.F. Waldemarin. 2000. Feeding of the neotropical river otter (Lontra longicaudis) in the costal region of the Rio Grande do Sul State, Southern Brazil. IUCN Otter Specialist Group Bull, Wageningen, 17: 6-13.

Eisemberg, J.F. \& K.H Redford. 1999. Mammals of the Neotropics: The Central Neotropics. Chicago, The University of Chigago Press, 609p.

FolHa SH. 22. 1986. Levantamento de Recursos Naturais: Ecologia, Geomorfologia, Pedologia, Vegetação, Uso potencial da Terra. Rio de Janeiro, IBGE, p. 541-632.

Gorman, M.L. \& B.J. Trowbridge. 1989. The Role of Odor in the Social Lives of Carnivores, p. 57-88. In: J.L. GitTLEmAN (Ed.). Carnivore Behavior, Ecology, and Conservation. New York, Cornel University Press, 620p.

Koch, W.R.; P.C. Milani \& K.M. Grosser. 2000. Guia Ilustrado de Peixes Parque do Delta do Jacuí. Porto Alegre, Fundação Zoobotânica do Rio Grande do Sul, 89p.

Krebs, C.J. 1998. Ecological Metodology. Menlo Park, University of British Columbia, $2^{\text {nd }}$ ed., 620p.

Larivière, S. 1999. Lontra longicaudis. Mammals Species, Lawrence, 609: 1-5.

PardinI, R. 1998. Feeding ecology of the neotropical river otter Lontra longicaudis in Atlantic Forest strem, south-estern Brazil. Journal of Zoology, London, 245: 385-391.

Pardini, R. \& E. Trajano. 1999. Use of shelters by the neotropical river otter (Lontra longicaudis) in atlantic forest stream, southeastern Brazil. Journal of Mammalogy, Lawrence, 80 (2): 600-610.

Passamani, M. \& S.L. Camargo. 1995. Diet of the river otter Lutra longicaudis in Furnas Reservoir, south-eastern Brazil. Otter Specialist Group Bull, Wageningen, 12: 32-34.

Quadros, J. \& E.L.A. Monteiro-Filho. 2001. Diet of the Neotropical Otter, Lontra longicaudis, in an Atlantic Forest Area, Santa Catarina State, Southern Brazil. Studies of the Neotropical Fauna and Environment, Nisse, 36: 15-21.

2002. Spraiting Sites of the Neotropical Otter, Lontra longicaudis, in an Atlantic Forest Area of Southern Brazil. Mastozoologia Neotropical / Journal of Neotropical Mammalogy, Mendoza, 9 (1): 39-46.

RedFord, K.H. 1997. A Floresta Vazia, p. 1-22. In: C. VallaresPÁduA \& R.E. Bodmer (Eds). Manejo e Conservação de Vida Silvestre no Brasil. Belém, MCT-CNPq, Sociedade Civil Mamirauá, 285p.

Soldateli M \& C. Blacher. 1996. Considerações preliminares sobre o número e distribuição espaço/temporal de sinais de Lutra longicaudis (Olfers, 1818) (Carnivora: Mustelidae) nas lagoas da Conceição e do Peri, Ilha de Santa Catarina, SC, Brasil. Biotemas, Florianópolis, 9: 38-64.

Sínola, R.M. \& C. Vaughan. 1995. Abundancia relatiava y actividad de marcaje de la nutria neotropical (Lutra 
longicaudis) en Costa Rica. Vida Silvestre Neotropical, Heredia, 4: 38-45.

Wemmer, C.; T.H. Kuns; G. Lundie-Jenkins \& W.J. Mcshea. 1996. Mammalian Sign, p. 157-176. In: D.E. WiLson; F.R. Cole; J.D. Nichols; R. Rudan \& M.S. Foster (Eds). Mensuring and
Monitoring Biological Diversity, Standard Methods for Mammals. Washington, Smithsonian Institution Press, 409p.

Zar, J.H. 1999. Biostatistical Analysis. New Jersey, Prentice Hall, $4^{\text {th }}$ ed, 663p.

Recebido em 12.VIII.2003; aceito em 21.I.2004.

Revista Brasileira de Zoologia 21 (1): 65-72, março 2004 